УДК 712.4

МРНТИ 87. 29.35

DOI 10.37238/1680-0761.2021.83(3).24

\author{
${ }^{1}$ Мамышева М.В.*, ${ }^{2}$ Кажымуратова Ж.С. \\ 1,2Западно-Казахстанский университет им. М. Утемисова, \\ Уральск, Казахстан \\ *Автор-корреспондент: mamyshevamv@gmail.com
}

E-mail: mamyshevamv@gmail.com

\title{
УЧЕТ И ИНВЕНТАРИЗАЦИЯ ЗЕЛЕНЫХ НАСАЖДЕНИЙ ЛАНДШАФТНО-АРХИТЕКТУРНОГО ОБЪЕКТА - ГОРОДСКОГО ПАРКА КУЛЬТУРЫ И ОТДЫХА Г. УРАЛЬСКА
}

\begin{abstract}
Аннотация. В данной статье рассматриваются вопросы учета и инвентаризации зеленых насаждений территории городского парка и приводятся результать их количественной и качественной оченки. Исследования проводились стандартными методами. Основной иелью натурного исследования явился анализ структуры существующих насаждений. Структура включает в себя определение видового состава, возрастной структуры, характера и плотности размещения растений. Всего было исследовано пятнадцать участков парковой территории, занятой зелеными насаждениями. В ходе исследования был проведен учет 5496 экземпляров на площади 16,5 га, среди которых 4882 экземпляра - деревья и 614 экземпляров кустарников и выяснено, что деревья занимают 82\% от площуади насаждений, а кустарники - 18\%; самые многочисленные виды: Acer tataricum. Ulmus parvifolia, Fraxinus americana, Betula pendula, Ulmus laevis, Populus alba, Populus nigra; средний возраст деревьев 26 лет; средняя высота деревьев 12,4 м.

Ключевые слова: зеленые насаждения; инвентаризаџия; инвентаризационная ведомость; таксачионный диаметр; древесно-кустарниковые насаждения; зеленый массив; парк; жизненная форма; видовой состав; количественный учет и оценка.
\end{abstract}

\section{Введение}

Расширение города и выход его за пределы исторически сложившихся границ, неконтролируемые вырубки деревьев, ухудшение состояния атмосферы вследствие увеличения выбросов выхлопных газов и отходов производств влияют на экологию и состояние окружающей среды. Растения обогащают воздух кислородом, увлажняют и очищают его, способствуют снижению шума, влияют на микроклимат территории.

Значение зеленых насаждений в городе трудно переоценить. Помимо выполнения рекреационной и декоративно-художественной функций они являются фильтром, который поглощает выхлопные газы автомобилей и вредные выбросы в атмосферу промышленных предприятий. Поэтому важно следить за их состоянием, проводить плановый мониторинг, высаживать новые растения и бережно относится ко всем имеющимся зеленым насаждениям.

В Послании народу Казахстана от 1 сентября 2020 г. Главой государства КасымЖомартом Токаевым было сказано следующее: «Охрана окружающей среды и экологическое развитие выходят на первый план казахстанской повестки дня. Этим вопросом занимается весь цивилизованный мир, и нам негоже оставаться в стороне от магистральной тенденции. 
Законодательно и нормативно нужно защитить национальные парки и другие природные богатства Казахстана, ужесточить уголовное и административное преследование граждан, совершающих правонарушения в этой сфере.

Необходимо уделить должное внимание экологическому воспитанию подрастающего поколения в школах и вузах» [1].

Поэтому сохранение зеленых насаждений, улучшение их состояния, наращивание зеленого пояса города является в настоящее время приоритетным.

Целью данной работы являлся учет зеленых насаждений посредством их инвентаризации.

В работе впервые представлены полные данные инвентаризации зеленых насаждений парка за последние тридцать лет. Актуальность работы определялась изменением экологической обстановки города и историко-краеведческой значимостью городского парка. На момент начала исследований оказалось, что на объекте за последние тридцать лет не проводилась полная инвентаризация зеленых насаждений парка, не представлено официальных документов или сведений о проведении развернутого учета зеленых насаждений и оценки их состояния. Полученные результаты в дальнейшем были включены в официальные документы парка.

\section{Материалы и методы исследования}

Территория городского парка культуры и отдыха занимает 24 га, из них 16,5 га заняты зелеными насаждениями (рис. 1).

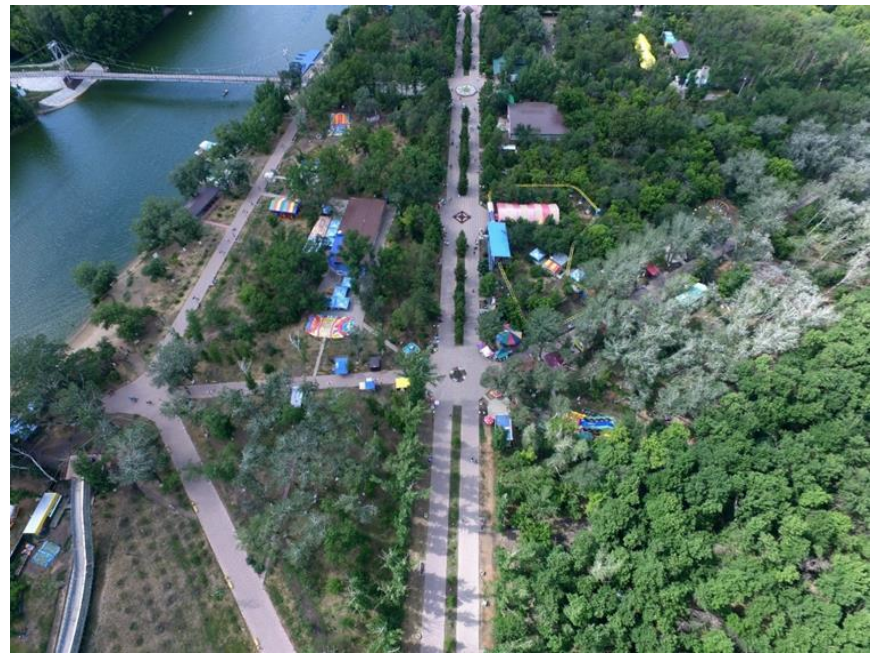

\section{Рисунок 1 - Городской парк культуры и отдыха (вид сверху)}

В ходе исследования использовалась методика проведения инвентаризации зеленых насаждений городов и населенных мест Республики Казахстан [2]. При этом нами определялись следующие показатели: количество деревьев и кустарников с определением формы насаждения, вид растения, таксационный диаметр каждого экземпляра, возраст и высота.

Для количественной оценки зеленых насаждений городского парка были привлечены в качестве помощников студенты естественно-географического факультета, специальности «Биология» Западно-Казахстанского университета им. М. Утемисова, а также волонтёры. Работа проводилась при поддержке общественной комиссии при акимате города и ЗападноКазахстанского эколого-географического общества. 
В целях удобства проведения учета территория была разделена на условные учетные участки, ограниченные дорожками или другими постоянными контурами внутренней ситуации (рис. 2).

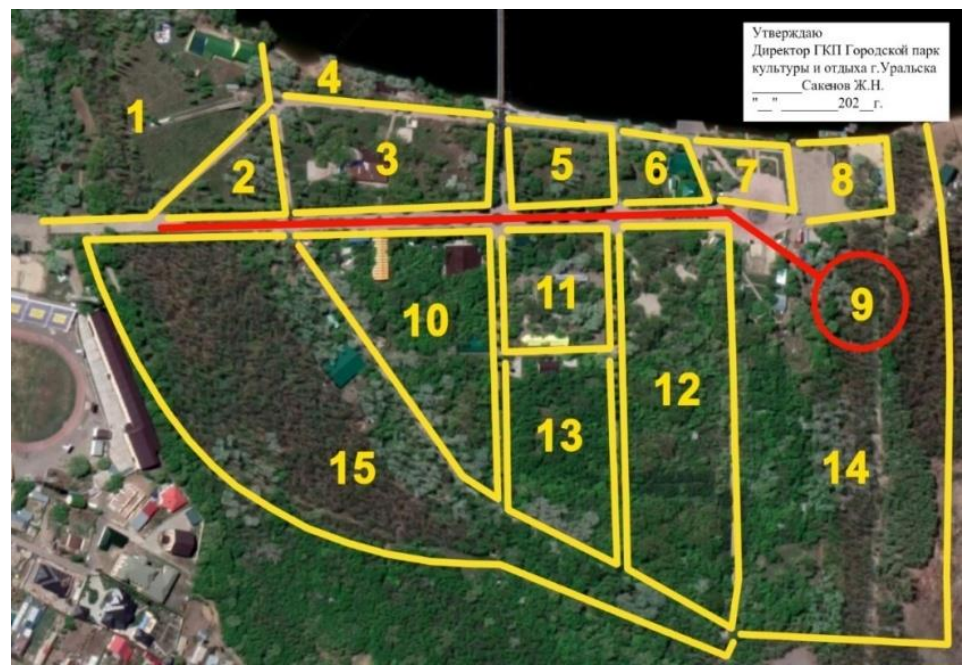

Рисунок 2 - Карта парка с учетными участками

Учетным участкам присваивались порядковые номера. Всего было выделено 15 участков. Два участка под номером 14 и 15 были отнесены к категории зеленого массива. В них описание проводилось с использованием методики геоботанического описания леса по Б. М. Каплану [3]. На каждом участке каждый растительный объект фиксировался и описывался по отдельности, каждому экземпляру присваивался порядковый номер. Инвентаризация проводилась в два этапа. На первом этапе осуществлялся сбор данных о зеленых насаждениях, оценивались их характеристики и состояние [4]. Эти данные заносились в дневник. На втором этапе (камеральном) данные из дневника интегрировались в базу данных в форме таблицы.

При измерении высоты насаждений нами использовалась рулетка (измерение невысоких экземпляров, подроста) и глазомерный метод.

Возраст деревьев рассчитывался:

1. по формуле: $\mathbf{M}=\mathbf{R} \times \mathbf{p}$, где

М-возраст,

$\mathrm{R}$-радиус (D/2),

p-годовой прирост дерева (табличное значение), (таб. 1,2) [5].

Таблииа 1 - Быстрорастущие и умереннорастущие деревья

\begin{tabular}{|c|c|c|c|c|}
\hline $\begin{array}{l}\text { Весьма } \\
\text { быстрорастущие }\end{array}$ & \multicolumn{2}{|l|}{ Быстрорастущие } & \multicolumn{2}{|l|}{ Умереннорастущие } \\
\hline прирост до 2 см & \multicolumn{2}{|l|}{ прирост $<=1$ см } & \multicolumn{2}{|l|}{ прирост 0,5-0,6 см } \\
\hline- & Лиственные & Хвойные & Лиственные & Хвойные \\
\hline $\begin{array}{l}\text { Робиния } \\
\text { ложноакациевая } \\
\text { Береза } \\
\text { бородавчатая } \\
\text { Ива белая } \\
\text { Павловния } \\
\text { Тополь черный }\end{array}$ & $\begin{array}{l}\text { Вяз } \\
\text { Катальпа } \\
\text { Ясень } \\
\text { обыкновенный }\end{array}$ & $\begin{array}{l}\text { Ель обыкновенная } \\
\text { Лиственница } \\
\text { европейская } \\
\text { Лиственница } \\
\text { сибирская } \\
\text { Сосна } \\
\text { обыкновенная }\end{array}$ & $\begin{array}{l}\text { Дуб черешчатый } \\
\text { Клен остролистый } \\
\text { Липа серцевидная }\end{array}$ & $\begin{array}{l}\text { Ель колючая } \\
\text { Ель Энгельмана } \\
\text { Можжевельник } \\
\text { виргинский } \\
\text { Туя западная }\end{array}$ \\
\hline
\end{tabular}




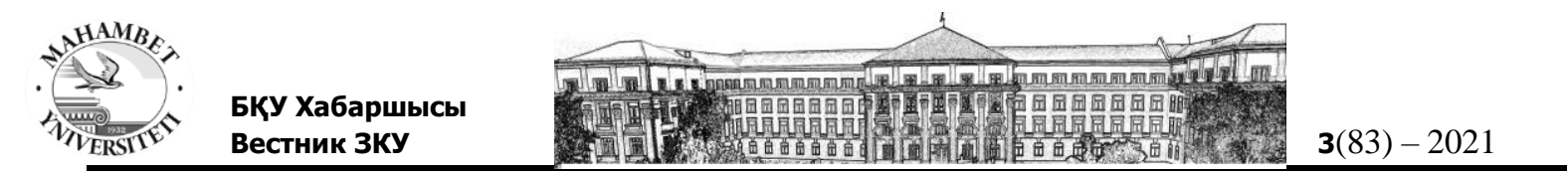

Таблица 2 - Медленнорастущчие деревья

\begin{tabular}{|c|c|c|c|}
\hline \multicolumn{2}{|l|}{ Медленнорастущие } & \multicolumn{2}{|l|}{ Очень медленнорастущие } \\
\hline прирост 0,2-0,25 см & & прирост 0,15 см & \\
\hline Лиственные & Хвойные & - & \\
\hline $\begin{array}{l}\text { Груша } \\
\text { Яблоня }\end{array}$ & $\begin{array}{ll}\text { Сосна } & \text { кедровая } \\
\text { сибирская } & \\
\text { Туя восточная } & \end{array}$ & $\begin{array}{lr}\text { Карликовые } & \text { формы } \\
\text { Карликовые } & \text { формы } \\
\text { Тис ягодный } & \\
\end{array}$ & $\begin{array}{r}\text { лиственных } \\
\text { хвойных }\end{array}$ \\
\hline
\end{tabular}

Составлен авторами

2. по формуле:B=1,6 х Д + 44,где

В - возраст дерева, лет;

Д - таксационный диаметр в см;

44 - коэффициент.

Этот способ определения - очень приблизительный, ошибка может составить от 5 до $15 \%$ в сторону увеличения возраста. При этом для дерева диаметром 20-44 см эта ошибка составляет около 5\%, свыше 44 лет - от 6 до 10\%: чем старше дерево, тем чаще оно попадает в неблагоприятные условия и тем сильнее будут колебания ширины годичного кольца.

3. по ветвям: у хвойного дерева пересчитывалось количество мутовок(ярусов кольцеобразного расположения веток) на стволе. К количеству мутовок прибавлялось 3 (сосна), 4 (ель), 5 (пихта) или 10 (кедр) лет, т.к. первая мутовка появляется не в первый год, а в разном возрасте в зависимости от породы дерева. Полученная сумма означала возраст дерева. У лиственного дерева возраст определялся также по годичным кольцам - но не ствола, а внешним кольцам ветви. Дело в том, что каждый год рост её начинается с верхушечной почки. В этом месте на ветке остаётся поперечный рубец в виде утолщениякольца. Первое кольцо образуется в месте отхождения от ствола.

На основании собранных данных были составлены сводные инвентаризационные ведомости. Пример ведомости представлен в таблице 3. 


\section{Таблицуа 3 - Инвентаризацчионная ведомость}

\begin{tabular}{|c|c|c|c|c|c|c|c|c|}
\hline $\begin{array}{l}\text { № } \\
\text { участка }\end{array}$ & $\begin{array}{l}\text { № } \\
\text { растения }\end{array}$ & $\begin{array}{l}\text { Форма } \\
\text { насаждения }\end{array}$ & $\begin{array}{l}\text { Жизненная } \\
\text { форма }\end{array}$ & Вид растения (Название породы) & Количество & $\begin{array}{l}\text { Диаметр } \\
\text { ствола, см }\end{array}$ & Высота, м & $\begin{array}{l}\text { Возраст, } \\
\text { лет }\end{array}$ \\
\hline \multirow[t]{15}{*}{5} & 1 & Групповая & Древесная & $\begin{array}{l}\text { Тополь белый } \\
\text { (Populus alba) }\end{array}$ & 1 & 51 & 15 & $23-25$ \\
\hline & 2 & & & $\begin{array}{l}\text { Подрост - Липа сердцевидная (Tília } \\
\text { cordáta Mill.) }\end{array}$ & 1 & & 1,45 & \\
\hline & 3 & & & $\begin{array}{l}\text { Тополь белый } \\
\text { (Populus alba) }\end{array}$ & 1 & 37,4 & 12 & $18-19$ \\
\hline & 4 & & & Липа сердцевидная (Tília cordáta Mill.) & 1 & 24,14 & 9 & 34 \\
\hline & 5 & & & Липа сердцевидная (Tília cordáta Mill.) & 1 & 23 & 8 & 42 \\
\hline & 6 & & & $\begin{array}{l}\text { Подрост - Липа сердцевидная (Tília } \\
\text { cordáta Mill.) }\end{array}$ & 1 & & 1,9 & \\
\hline & 7 & & & - & 1 & & 3,5 & \\
\hline & 8 & & & $\begin{array}{l}\text { Подрост - Клен обыкновенный } \\
\text { (Acer negundo ) }\end{array}$ & 1 & & 1,6 & \\
\hline & 9 & & & $\begin{array}{l}\text { Подрост - Липа сердцевидная (Tília } \\
\text { cordáta Mill.) }\end{array}$ & 1 & & 3,5 & \\
\hline & 10 & & & - & 1 & & 1,5 & \\
\hline & \multirow[t]{5}{*}{11} & & & Клен татарский (Acer tataricum) & \multirow[t]{5}{*}{5} & 8,12 & \multirow[t]{5}{*}{3,5} & $14-15$ \\
\hline & & & & - & & 6 & & 11 \\
\hline & & & & - & & 8,9 & & 16 \\
\hline & & & & - & & 8,6 & & 15 \\
\hline & & & & - & & 3,5 & & 6,5 \\
\hline & \multirow[t]{2}{*}{12} & & & Липа сердцевидная (Tília cordáta Mill.) & 4 & 19 & \multirow[t]{2}{*}{$18-20$} & 32 \\
\hline & & & & & & 22 & & 40 \\
\hline
\end{tabular}

Составлен авторами 


\section{Результаты}

В процессе инвентаризации зеленых насаждений на объекте было выявлено 2996 экземпляров древесно-кустарниковых пород на участках с 1 по 13, из них 2447 деревьев и 549 кустарников, относящихся к 9 порядкам, 15 семействам, 24 родам, 25 видам деревьев и 10 видам кустарников. Были определены как групповые, так и одиночные формы насаждений. Видовой состав древесно-кустарниковых насаждений представлен в таблице 4.

На 14 и 15 участках, относящихся к категории зеленого массива, произрастает около 2500 экземпляровдеревьев, относящихся к 7 порядкам, 9 семействам, 8 родам, 8 видам и кустарников, относящихся к 2 порядкам, 3 семействам, 3 родам и 3 видам.

Таблица 4 - Видовой состав древесно-кустарниковых насаждений парка

\begin{tabular}{|c|c|c|c|c|c|c|}
\hline № & $\begin{array}{l}\text { Жизненная } \\
\text { форма }\end{array}$ & Название растения & Семейство & Род & Вид & $\begin{array}{l}\text { Кол- } \\
\text { во } \\
\text { (шт) }\end{array}$ \\
\hline 1 & древесная & Береза бородавчатая & Betulaceae & Betula & Betula pendula & 377 \\
\hline 2 & - & Вяз мелколистный & Ulmaceae & Ulmus & Ulmus parvifolia & 458 \\
\hline 3 & - & Вяз гладкий & Ulmaceae & Ulmus & Ulmus laevis & 274 \\
\hline 4 & - & Тополь белый & Salicaceae & Populus & Populus alba & 262 \\
\hline 5 & - & Тополь черный & Salicaceae & Populus & Populus nigra & 209 \\
\hline 6 & - & Липа сердцевидная & Malvaceae & Tilia & Tilia cordata & 112 \\
\hline 7 & - & Клен платановидный & Sapindaceae & Acer & Acer plantanoides & 63 \\
\hline 8 & - & Клен обыкновенный & Sapindaceae & Acer & Acer negundo & 118 \\
\hline 9 & - & Ясень американский & Oleaceae & Fraxinus & $\begin{array}{l}\text { Fraxinus } \\
\text { americana }\end{array}$ & 185 \\
\hline 10 & - & Ива плакучая & Salicaceae & Salix & Salix babylonica & 18 \\
\hline 11 & - & Ива белая & Salicaceae & Salix & Salix alba & 1 \\
\hline 13 & - & Дуб черешчатый & Fagaceae & Quercus & Quercus robur & 77 \\
\hline 14 & - & Ель европейская & Pinaceae & Picea & Picea abies & 89 \\
\hline 15 & - & $\begin{array}{l}\text { Лиственница } \\
\text { сибирская }\end{array}$ & Pinaceae & Larix & Larix sibirica & 52 \\
\hline 16 & - & Сосна обыкновенная & Pinaceae & Pinus & Pinus silvestris & 104 \\
\hline 17 & - & $\begin{array}{l}\text { Робиния } \\
\text { ложноакациевая }\end{array}$ & Fabaceae & Robinia & $\begin{array}{l}\text { Robinia } \\
\text { pseudoacacia }\end{array}$ & 16 \\
\hline 18 & - & $\begin{array}{l}\text { Каштан конский } \\
\text { обыкновенный }\end{array}$ & Sapindaceae & Aesculus & $\begin{array}{l}\text { Aesculushippocast } \\
\text { anum }\end{array}$ & 3 \\
\hline 19 & - & $\begin{array}{l}\text { Рябина } \\
\text { обыкновенная }\end{array}$ & Rosaceae & Sorbus & Sorbus aucuparia & 4 \\
\hline 20 & - & $\begin{array}{l}\text { Вишня } \\
\text { обыкновенная }\end{array}$ & Rosaceae & Prunus & Prunus cerasus & 1 \\
\hline 21 & - & Яблоня домашняя & Rosaceae & Malus & Malus domestica & 1 \\
\hline 22 & - & Яблоня дикая & Rosaceae & Malus & Malus sylvestris & 12 \\
\hline 23 & - & Груша дикая & Rosaceae & Pyrus & Pyrus communis & 8 \\
\hline 24 & $\begin{array}{l}\text { кустарников } \\
\text { ая }\end{array}$ & Калина красная & Adoxaceae & Viburnum & Viburnum opulus & 1 \\
\hline 25 & древесная & Слива домашняя & Rosaceae & Prunus & Prunus domestica & 1 \\
\hline 26 & $\begin{array}{l}\text { кустарников } \\
\text { ая }\end{array}$ & Клен татарский & Sapindaceae & Acer & $\begin{array}{l}\text { Acer } \\
\text { tataricum }\end{array}$ & 446 \\
\hline
\end{tabular}


Продолжение таб. 4

\begin{tabular}{|l|l|l|l|l|l|l|}
\hline 27 & - & $\begin{array}{l}\text { Крушина } \\
\text { слабительная }\end{array}$ & Rhamnaceae & Rhamnus & $\begin{array}{l}\text { Rhamnus } \\
\text { cathartica }\end{array}$ & 16 \\
\hline 28 & - & $\begin{array}{l}\text { Сирень } \\
\text { обыкновенная }\end{array}$ & Oleaceae & Syringa & Syringa vulgaris & 35 \\
\hline 29 & - & Слива колючая & Rosaceae & Prunus & Prunus spinosa & 4 \\
\hline 30 & - & Акация жёлтая & Fabaceae & Caragana & $\begin{array}{l}\text { Caragana } \\
\text { arborescens }\end{array}$ & 21 \\
\hline 31 & - & $\begin{array}{l}\text { Лещина } \\
\text { обыкновенная }\end{array}$ & Betulaceae & Corylus & Corylus avellana & 18 \\
\hline 32 & - & Ирга обыкновенная & Rosaceae & $\begin{array}{l}\text { Amelanch } \\
\text { ier }\end{array}$ & Amelanchier ovalis & 1 \\
\hline 33 & - & $\begin{array}{l}\text { Черёмуха } \\
\text { обыкновенная }\end{array}$ & Rosaceae & Prunus & Prunus padus & 2 \\
\hline 34 & - & Шиповник собачий & Rosaceae & Rosa & Rosa canina & 1 \\
\hline 35 & - & Жимолость татарская & Caprifoliaceae & Lonicera & Lonicera tatarica & 5 \\
\hline
\end{tabular}

По количеству экземпляров наиболее многочисленны представители семейств: Betulaceae, Ulmaceae, Salicaceae, Oleaceae, Sapindales. Самые многочисленные виды: Клен татарский (Acer tataricum) - 446 шт., Вяз мелколистный (Ulmus parvifolia) - 458 шт., Ясень американский (Fraxinus americana) - 185 шт., Береза бородавчатая (Betula pendula) - 377 шт., Вяз гладкий (Ulmus laevis) - 274 шт., Тополь белый (Populus alba) - 262 шт., Тополь черный (Populus nigra) - 209 шт. Видовой состав хвойных деревьев представлен: Елью европейской (Picea abies) - 89 шт., Лиственницей сибирской (Larix sibirica) - 52 шт., Сосной обыкновенной (Pinus silvestris) - 104 шт.

Самым богатым по видовому разнообразию является 10 участок, где произрастает 30 видов древесно-кустарниковых насаждений; самым бедным - 9 участок, представлен одним видом Елью обыкновенной (Picea abies).Средняя высота древесно-кустарниковых насаждений на инвентаризуемых участках с 1 по 13 составила 12,4 м. Старовозрастные деревья Дуб черешчатый (Quercus robur) - 186 лет и Сосна обыкновенная (Pinus silvestris) - 190 лет. Средний возраст древесно-кустарниковых насаждений на тринадцати инвентаризуемых участках - 26 лет, среди них возраст 11 экземпляров достигает более 100 лет.

\section{Заключение}

Таким образом, в ходе исследования был проведен учет 5496 экземпляров на площади 16,5 га, среди которых 4882 экземпляра - деревья и 614экземпляров кустарников и выяснено, что деревья занимают $82 \%$ от площади насаждений, а кустарники - $18 \%$;самые многочисленные виды: Acer tataricum. Ulmus parvifolia, Fraxinus Americana, Betula pendula,Ulmus laevis, Populus alba,Populus nigra; средний возраст деревьев 26 лет; средняя высота деревьев 12,4 м.

На основании собранных данных была создана инвентаризационная ведомость зеленых насаждений парка по участкам. Согласно типовым правилам содержания и защиты зеленых насаждений, указанных в приказе Министра национальной экономики Республики Казахстан от 20 марта 2015 года № 235, данные инвентаризации учетного объекта должны заноситься в реестр зеленых насаждений.

Проведенное исследование необходимо для улучшения состояния зеленых насаждений в ближайшем будущем, применения результатов исследования в научных и иных целях, т. к. городской парк культуры и отдыха представляет историческую и научно практическую ценность. 


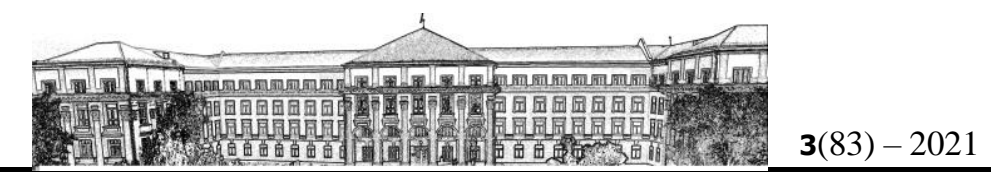

\section{ЛИТЕРАТУРА}

[1] Послание Главы государства Касым - Жомарта Токаева народу Казахстана. 1 сентября 2020 2.

[2] Есполов Т.И., Байзаков С.Б. Методика проведения инвентаризации зеленых насаждений городов и населенных мест Республики Казахстан. - Алматы, 2006 - С.23-27.

[3] Каплан Б. М. Изучение лесной растительности. - Москва, 2009 г. - С 63 - 75

[4] Конашова, С. И. Состояние насаждений в городских парках / С. И. Конамова, Т. Х. Абдулов // Вестник БГАУ. - 2012. - № 2. - С. 62-65.

[5] Скорость роста деревьев. Таблица роста и последние исследования [Электронный ресурс] - Режим доступа: https://nature-time.ru/2014/01/skorost-rosta-derevev/.

\section{REFERENCES}

[1] Poslanie Glavy gosudarstva Kasym - Zhomarta Tokaeva narodu Kazakhstana. 1 sentyabrya $2020 \mathrm{~g}$. [Address of the Head of State Kassym-JomartTokayev to the people of Kazakhstan. September 1, 2020] [in Russian].

[2] Espolov T.Y. \& Baizakov S.B. (2006). Metodika provedeniya inventarizacii zelenykh nasazhdenij gorodov $i$ naselenykh mest Respubliki Kazakhstan [Methodology of carrying out inventory of green spaces of cities and settlements of the Republic of Kazakhstan] Almaty, 23-27 [in Russian].

[3] Kaplan B. M. (2009) Izuchenie lesnoj rastitelnosti [Study of forest vegetation] Moskva, 63 - 75 [in Russian].

[4] Konashova S. I. \& T. H. Abdulov (2012) Sostoyanie nasazhdenij v gorodskikh parkakh [The state of plantings in urban parks] - Vestnik BGAU, 2, 62-65 [in Russian].

[5] Scorost' rosta derev'ev. Tablica rosta i poslednie issledovaniya [The speed of tree growth. Growth chart and recent research] Retrieved from: https://nature-time.ru/2014/01/skorostrosta-derevev/ [in Russian].

\section{Мамышева М.В., Қажымуратова Ж.С. ЛАНДШАФТТЫК - АРХИТЕКТУРАЛЫК ОБЬЕКТ РЕТІНДЕ ОРАЛ ҚАЛАЛЫҚ МӘДЕНИ ЖӘНЕ ДЕМАЛЫС САЯБАҒЫНДАҒЫ ЖАСЫЛ ЖЕЛЕКТЕРДІ ЕСЕПКЕ АЛУ ЖӘНЕ ТУГЕНДЕУ}

Аннотация. Мақалада қалалық мәдени және демалыс саябағындағы жасыл желектерді түгендеп және есепке ала отырып, олардың сандық және сапалық бағалау нәтижесі берілген.Шартты түрде бөлінген 15 сектордағы сүректі өсімдіктеодің түрлік құрамы, жасы, жағдайы және орналасу жиілігі зерттелген.Зерттеу нәтижесінде, 16,5 га .орналасқан 5496 өсімдіктің саны тіркелсе, оның 4882-сі ағаштар, 614-ін бұталар құраса, ағаштардың жалпы аумағы- 82\%, бұталар-18\% аумақты алып жатырғандығы анықталды.Зерттеу жұмыстары баршаға ортақ әдістермен жүргізілген, негізгі мақсаты жасыл желектерді құрылымдық талдау болып табылады.Көп кездесетіндері: Acer tataricum. Ulmus parvifolia, Fraxinus Americana, Betula pendula, Ulmus laevis, Populus alba, Populus nigra, ағаштардың орташа жасы 26 жаста болса, орташа биіктігі 12,4 метр.

Түйінді сөздер: жасыл желектер, түгендеу, түгендеу кестесі, жасыл аймақ, саябақ, тіршілік формасы, түрлік құрамы, сандық есеп, бағалау. 


\section{Бқу Хабаршысы \\ Вестник ЗКУ \\ Mamysheva Marina, Kazhymuratova Zhannat \\ ACCOUNTING AND INVENTORY OF GREEN SPACES OF THE LANDSCAPE AND ARCHITECTURAL OBJECT-THE CITY PARK OF CULTURE AND RECREATION
OF URALSK}

Annotation. This article discusses the issues of accounting and inventory of green spacesin the territory of the city park and provides the results of their quantitative and qualitative assessment. The studies were conducted using standard methods. The main purpose of the field study was to analyze the structure of existing plantings. The structure includes the determination of the species composition, age structure, nature and density of plant placement. In total, fifteen sections of the park territory occupied by green spaces were examined. In the course of the study, 5,496 specimens were recorded on an area of 16.5 hectares, among which 4,882 specimens were trees and 614 shrubs, and it was found that trees occupy $82 \%$ of the area of plantings, and shrubs $-18 \%$; the most numerous species: Acer tataricum. Ulmusparvifolia, Fraxinus Americana, Betula pendula, Ulmuslaevis, Populus alba, Populusnigra; average tree age 26 years; average tree height $12.4 \mathrm{~m}$.

Keywords: green spaces; inventory; inventory list; taxation diameter; tree and shrub plantings; green area; park; life form; species composition; quantitative accounting and evaluation. 